\title{
GAMBARAN JAMUR PENYEBAB TINEA UNGUIUM PADA SEDIAAN KEROKAN KUKU KAKI BURUH PERUSAHAAN EKSPOR IMPOR KEPITING
}

\author{
Herlina Rezky Suryanty ${ }^{1)}$, Mujahidah Basarang ${ }^{2)}$ dan Nurul Ni'ma Azis ${ }^{2)}$. \\ ${ }^{1)}$ RS Samaritan \\ ${ }^{2)}$ Teknologi Laboratorium Medis, Politeknik Kesehatan Muhammadiyah Makassar \\ Alamat Korespondensi: herlinaaars@gmail.com
}

\begin{abstract}
Artikel info:
Received: Desember 2021

Revised: Desember 2021

Accepted: Desember 2021

Publish: Desember 2021
\end{abstract}

\begin{abstract}
Abstrak
Tinea unguium adalah penyakit infeksi jamur yang disebabkan oleh Tricophyton rubrum dan Tricophyton mentagrophytes. Infeksi ini diketahui menyebabkan kuku menjadi rusak seperti mulai menghitam dan sedikit terangkat. Kelompok masyarakat yang paling sering terkena infeksi ini adalah masyarakat yang mempunyai kegiatan di daerah yang lembab. Tujuan penelitian ingin mengetahui gambaran jamur yang menjadi penyebab penyakit Tinea unguium pada sediaan kerokan kuku kaki buruh perusahaan ekspor impor kepiting yang ada di kota Makassar. Jenis penelitian bersifat observasi laboratorik, dengan mengambil kerokan kuku kaki buruh perusahaan ekspor impor kepiting sebanyak 10 orang dengan kriteria kuku rusak dan menguning atau menghitam. Penelitan ini dilakukan pada bulan April 2019. Pemeriksaan sampel menggunakan metode pengamatan langsung menggunakan $\mathrm{KOH}$ 40\% dan dilanjutkan dengan kultur sampel pada media PDA (Potato Dextrose Agar). Sampel yang tumbuh diamati di bawah mikroskop untuk mengidentifikasi jenis jamur berdasarkan ciri morfologi. Berdasarkan hasil pemeriksaan mikroskopis, ditemukan 1 sampel positif jamur penyebab tinea unguium yaitu Trichophyton interdigitale dari 10 sampel yang ada.
\end{abstract}

Kata Kunci: Tinea unguium, kerokan kuku kaki, PDA

\begin{abstract}
Tinea unguium is a fungal infection caused by Tricophyton rubrum and Tricophyton mentagrophytes. This infection is known to cause the nails to become damaged as they begin to turn black and slightly lift. The community groups most often affected by this infection are people who have activities in humid areas. The purpose of the study was to find out the description of the fungus that causes Tinea unguium disease in the preparation of toenail scrapings of laborers of crab export-import companies in Makassar city. This type of research is laboratory observation, by taking toenail scrapings of laborers from export-import crab companies as many as 10 people with the criteria of damaged and yellowed or blackened nails. This research was conducted in April 2019. Sample examination used direct observation method using $40 \% \mathrm{KOH}$ and followed by sample culture on PDA (Potato Dextrose Agar) media. The growing sample was observed under a microscope to identify the type of fungus based on morphological characteristics. Based on the results of microscopic examination, 1 positive sample of the fungus that causes tinea unguium, namely Trichophyton interdigitale, was found from 10 samples.
\end{abstract}

Keyword: Tinea unguium, toe nails scraping, PDA 


\section{PENDAHULUAN}

Jamur adalah organisme heterotrofik yang memerlukan senyawa organik untuk nutisinya. Banyak jenis jamur yang ada di sekitar kita. Ada beberapa jamur yang menguntungkan dan ada juga yang bersifat merugikan. Salah satu jenis jamur yang merugikan adalah dermatofita penyebab dermatofitosis. Dermatofitosis adalah infeksi jamur pada jaringan yang mengandung zat tanduk, misalnya stratum korneum pada epidermis, rambut dan kuku. Patogenesis dermatofitosis tergantung pada faktor lingkungan, antara lain iklim yang panas, hygiene perorangan, sumber penularan, penggunaan obat steroid, antibiotik, sitostatika, imunogenitas, kemampuan invasi organisme, lokasi infeksi dan respon imun (Brooks GF et all, 2017).

Salah satu klasifikasi dermatofitosis adalah tinea unguium yang merupakan infeksi pada lempeng kuku yang disebabkan oleh jamur kulit dermatofita, non dermatofita maupun yeast. Beberapa penelitian menyebutkan bahwa $80-90 \%$ kasus tinea unguium disebabkan oleh jamur dermatofita, khususnya Trichophyton rubrum dan Trichophyton mentagrophytes, kasus tinea unguium disebabkan oleh jamur dermatofita, khususnya Trychophyton rubrum dan Trychophyton mentagrophytes, 5-17 \% lainnya disebabkan oleh yeast terutama Candida sp, dan 3-5 \% disebabkan oleh non-dermatofita seperti Aspergillus sp atau Scopulariopsis. (Afshar, 2014).

Gejala yang seringkali nampak pada infeksi ini adalah kerusakan pada kuku, diantaranya kuku menjadi lebih tebal dan nampak terangkat dari dasar perlekatannya atau onycholysis, pecahpecah, tidak rata dan tidak mengkilat lagi, serta perubahan warna lempeng kuku menjadi putih, kuning, coklat hingga hitam (Baraldi et all, 2014).

Menurut penelitian Isnawarni (2015) ditemukan 10 sampel yang terinfeksi tinea unguium dan jamur yang ditemukan ialah jamur Aspergillus sp.
Tinea unguium mungkin tidak menyebkan mortalitas, namun menimbulkan gangguan klinis yang signifikan secara alami mengurangi estetika, bersifat kronis, dan sulit diobati, hal tersebut kemudian dapat mengganggu kenyamanan dan menurunkan kualitas hidup penderita. Infeksi jamur dapat meningkatkan infeksi bakteri, selulit, urticaria kronis, dan sebagai reservoir jamur yang kemudian menginfeksi bagian tubuh lainnya serta dapat ditransmisikan atau ditularkan ke individu lainnya (Baraldi et all, 2014).

Banyak kasus tinea unguium terjadi di kalangan masyarakat karena Indonesia adalah negara tropis dan salah satu penyebabnya adalah pemakaian barangbarang yang mudah lembab dengan jangka waktu lama dan sering. Salah satu contohnya ialah pemakaian sepatu bot.

Sepatu bot banyak digunakan oleh kalangan masyarakat, seperti petani, pedagang ikan di pasar, nelayan, buruh pabrik dan masih banyak profesi lainnya. Penggunaan sepatu bot yang terlalu lama biasanya dapat menimbulkan kelembaban. Buruh ekspor impor kepiting kota Makasar pada umumnya bekerja menggunakan sepatu bot dengan jangka waktu cukup lama yaitu dari pagi hingga sore atau malam hari setiap harinya. Berdasarkan survei peneliti terlihat beberapa buruh yang kuku kakinya nampak seperti ciri-ciri penderita tinea unguium, oleh karena itu peneliti tertarik untuk melakukan penelitian tentang gambaran infeksi tinea unguium pada buruh yang ada di perusahaan tersebut.

\section{METODE PENELITIAN} Alat dan Bahan

Alat dan bahan yang digunakan pada penelitian ini ialah gunting kuku, cawan porselin, pipet tetes, ose, kaca objek, kaca penutup, pinset, mikroskop, media PDA (Potato Dextrose Agar), $\mathrm{KOH} 40 \%$, dan kapas alkohol $70 \%$. 


\section{Prosedur Kerja \\ Pengumpulan sampel}

Sampel dikumpulkan dari buruh perusahaan ekspor impor kepiting dengan cara menggunakan gunting kuku. Mulamula kaki yang sudah masuk kriteria dibersihkan menggunakan kapas alkohol $70 \%$, kemudian ambil bagian ujung kaki yang diduga terinfeki jamur, kemudian kuku dimasukkan ke dalam wadah steril.

\section{Sterilisasi}

Sterilisasi adalah tahap untuk mematikan semua bentuk kehidupan mikroorganisme. Sterilisasi pada penelitian ini dilakukan pada semua alat yang akan digunakan dan pada kuku kaki buruh Perusahaan ekspor impor kepiting dengan menggunakan kapas alkohol 70\%.

\section{Pembuatan media}

Media yang digunakan dalam penelitian ini adalah media PDA (Potato Dextrose Agar). Cara pembuatannya yaitu, timbang PDA sebanyak $8,6 \mathrm{~g}$, selanjutnya dimasukkan ke dalam Erlenmeyer dan ditambahkan aquades sebanyak $220 \mathrm{~mL}$, lalu diukur $\mathrm{pH}$ 5,6 \pm 2 . Media dipanaskan menggunakan hot plate sampai larut. Media disterilkan di dalam autoclave selama 15 menit dengan suhu $121^{\circ} \mathrm{C}$, dengan tekanan 1-2 atm. Setelah media dikeluarkan dari autoclave, media didiamkan hingga dingin sampai suhu 45$50{ }^{\circ} \mathrm{C}$. Ditambahkan kloramfenicol 0,01g ke dalam media untuk menghambat pertumbuhan bakteri. Media PDA dituang ke dalam cawan porselin sebanyak 15-20 $\mathrm{mL}$ dan dibiarkan memadat.

\section{Pemeriksaan mikroskopik metode langsung}

Sampel kerokan kuku kaki ditambahkan $\mathrm{KOH} 40 \%$ sebanyak 1 tetes lalu di amati.

\section{Kultur sampel}

Sampel kerokan kaki yang sudah dikumpulkan kemudian diinokulasi pada PDA (Potato Dextrose Agar) dengan kloramfenikol dan diinkubasi pada suhu $37 \mathrm{C}$, cawan diperiksa setiap hari dari hari pertama sampai hari terakhir (Tjekyan, 2015).

\section{Pemeriksaan mikroskopik}

Setelah 3-5 hari jamur akan tumbuh pada media. Jamur yang telah tumbuh akan diambil menggunakan ujung ose lalu diletakkan di atas kaca objek kemudian ditambahkan dengan 1 tetes $\mathrm{KOH} 40 \%$ dan diperiksa dengan perbesaran mulamula 10x lalu 40x.

\section{Interprestasi hasil}

Interprestasi hasil dari penelitian ini ialah ditemukan jamur Trichophyton rubrum dan Trichophyton mentagrophytes.

\section{Analisa Data}

Data disajikan dalam bentuk tabel dan dinarasikan secara deskriptif.

\section{HASIL DAN PEMBAHASAN}

Berdasarkan penelitian gambaran jamur penyebab tinea unguium pada sediaan kerokan kuku kaki buruh perusahaan ekspor impor kepiting dengan metode mikroskopik langsung dan kultur jamur menggunakan media PDA (Potato Dextrose Agar) yang sudah dilakukan selama 7 hari didapatkan dari 10 sampel sediaan kerokan kuku kaki buruh perusahaan ekspor impor kepiting 10 sampel semua positif jamur. Jamur yang didapatkan ialah jamur Apergillus $S p$ dan jamur Exophiala.

Dari 10 sampel yang telah diperiksa, sampel $F$ positif jamur penyebab tinea unguium yaitu Trichophyton interdigitale dan 9 sampel lainnya negatif jamur penyebab tinea unguium.

Tabel 1. Hasil pemeriksaan kultur jamur pada sedian kuku kaki

\begin{tabular}{ccl}
\hline $\begin{array}{c}\text { Kode } \\
\text { Sampel }\end{array}$ & Hasil & \multicolumn{1}{c}{ Keterangan } \\
\hline A & Negatif & Exophiala $s p$ \\
B & Negatif & Exophiala $s p$ \\
C & Negatif & Aspergillus $s p$ \\
D & Negatif & Aspergillus $s p$ \\
E & Negatif & Aspergillus $s p$ \\
F & Positif & Trichophyton \\
& & interdigitale, \\
& & dan Exophiala \\
& & $s p$ \\
\hline
\end{tabular}




\begin{tabular}{cll}
\hline $\mathrm{G}$ & Negatif & Exophiala $s p$ \\
$\mathrm{H}$ & Negatif & Exophiala $s p$ \\
$\mathrm{I}$ & Negatif & Exophiala $s p$ \\
$\mathrm{~J}$ & Negatif & Aspergillus $s p$ \\
\hline
\end{tabular}

Dari 10 sampel maka diperiksakan jamur pada pemeriksaan mikroskopik tanpa kultur didapatkan hasil negatif dan pada pemerikaan mikroskopik setelah dikultur dari 10 sampel didapatkan semua positif jamur dengan jenis yang berbedabeda. Dalam kasus tinea unguium yang menjadi jamur penyebab utamanya adalah Trichophyton Sp.

Dalam sampel A dan B ditemukan jamur Exophiala. Pada sampel C, D dan E ditemukan jamur Aspergillus Sp. Pada sampel $F$ ditemukan 2 jamur yaitu jamur Trichophyton dan jamur Exophiala. Pada sampel G, H dan I juga ditemukan jamur Exophiala. Pada sampel J ditemukan jamur Aspergillus Sp.

Dalam penelitian ini ditemukan hanya 1 sampel yang positif jamur penyebab penyakit tinea unguium itu sendiri yaitu jamur Trichophyton interdigitale. Beberapa sampel ditemukan jamur Aspergillus $S p$ dikarenakan karena jamur jenis ini bisa tumbuh dimana saja, sebagaiman yang kita ketahui buruh perusahaan ekspor impor kepiting ini memakai sepatu bot dan itu salah satu faktor adanya resiko untuk menumbuhkan jamur jenis Aspergillus sp di kuku kaki mereka. Jamur lain yang ditemukan lagi pada penelitian ini adalah jamur Exophiala, jamur ini bersifat oligotrofik, terutama terjdi pada frekuensi rendah di lingkungan yang rendah nutrisi (Harris, 2009).

Jamur yang didapatkan lagi pada penelitian ini ialah jamur Trichophyton interdigitale. Jamur Trichophyton interdigitale adalah jamur antropofilik yang merupakan penyebab umum tinea pedis dan kadang-kadang invasi lempeng kuku superfisial pada manusia, dan spesies ini dapat dianggap sebagai cabang klon dari Trichophyton mentagrophytes dengan ciri-ciri, berwarna putih sampai putih kekuningan yang agak terang atau berwarna violet merah kadang bahkan berwarna pucat kekuningan hingga coklat. Koloninya seperti putih hingga krem dengan permukaan seperti tumpukan kapas (tidak berpigmen) dan menginfeksi daerah lembut antara jari-jari kaki. Infeksi ini dapat menimbulkan gejala berupa gatal, kemerahan, atau peradangan kulit di antara jari-jari kaki yang terlihat selalu tampak basah. (De Hoog et al, 2016).

Trichophyton interdigitale adalah bagian dari Trichophyton mentagrophytes, secara mikroskopis hifa seperti spiral, conidhiopora pendek, macroconidia jarang tampak, halus, dindingnya tipis yang terdiri dari 3-5 sel dan microconidia hanpir semua berbentuk bundar, bergerombol seperti buah anggur. Maka dari itu jamur ini juga termasuk penyebab penyakit Tinea unguium dan ditemukan pada kuku kaki buruh perusahaan ekspor impor kepiting kota Makassar.

Tinea unguium adalah suatu penyakit yang disebabkan oleh jamur. Penyakit ini menyerang pada lempeng kuku yang ditandai dengan kuku yang sudah rusak dan menguning bahkan menghitam. Pada kasus tinea unguium umumnya disebabkan oleh jamur Trichophyton $s p$, namun pada penelitian ini didapatkan jamur ekunder yang terkontaminasi seperti jamur Aspergillus $s p$ dan Exophiala. Pada penelitian yang dilakukan juga oleh Isnawarni ditemukan juga jamur sekunder yang dapat menyebabkan kuku kaki yang rusak yang menunjukan hasil positif jamur Aspergillus sp pada 10 sampel petugas TPAS Antang kota Makassar.

Kasus Tinea unguium di negara Indonesia banyak dialami oleh beberapa pekerja di Indonesia seperti petugas sampah, penjual ikan, dan buruh yang pekerjaannya berada di tempat yang beresiko terkena penyakit tersebut. Hal ini dipengaruhi oleh kondisi geografis dan iklim Indonesia. $T$. interdigitale dikaitkan dengan lokasi geografis (Taghipour et al., 2019). 


\section{KESIMPULAN DAN SARAN}

Dari 10 sampel sediaan kerokan kuku kaki buruh perusahaan ekspor impor kepiting didapatkan 9 sampel negatif dan 1 sampel positif Trichophyton inerdigitale.

Saran dari penelitian ini ialah pada saat pembuatan media lebih berhati-hati agar tidak terkontaminasi dan disarankan untuk penelitian selanjutnya untuk meningkatkan jumlah sampel dan untuk mendapatkan jenis jamur lain yang menjadi penyebab penyakit tinea unguium.

\section{DAFTAR PUSTAKA}

Afshar $\mathrm{P}$ Khodavaisy $\mathrm{S}$ KSGMRT. (2014). Onychomycosis in NorthEast of Iran. Iran J Micobiology.

Baraldi A, et all, 2014. Human Nail Place Modifications for Topical Therapy Pharm Res (Online), http://link.springer.com/10.10071 511095-014-1562-5, diunduh 12 Juni 2015.

Brook GF et al. (2007). Mycology. In: medical Microbiology 24 ed. New
York: The Mc.Graw-Hill Company.

De Hoog et al. (2016). Mycology Online (Online). (https://mycologi. adelaide.edu.eu, diunduh 15 Desember 2016).

Harris. (2009). Exophiala spinifera sebagai penyebab Phaeohyphomycosis kulit: Studi kasus dan tinjauan literature (Online). (https://www.ncbi.nlm.nih.gov/p mc/articles, diunduh 17 September 2010).

Taghipour, S. et al. (2019) 'Trichophyton mentagrophytes and $\mathrm{T}$ interdigitale genotypes are associated with particular geographic areas and clinical manifestations', Mycoses, 62(11), pp. 1084-1091. doi: $10.1111 /$ myc.12993.

Tjekyan R M S. (2015). Nilai Diagnostik Dermathophyte Strip Test pada Pasien Tinea unguium 2(1): 2024. 